\title{
Endocannabinoid-Dependent Homeostatic Regulation of Inhibitory Synapses by Miniature Excitatory Synaptic Activities
}

\author{
Si-yu Zhang, ${ }^{1 \star}$ Min Xu, ${ }^{1 \star}$ Qing-long Miao, ${ }^{1}$ Mu-ming Poo, ${ }^{1,2}$ and Xiao-hui Zhang ${ }^{1}$ \\ ${ }^{1}$ Institute of Neuroscience and State Key Laboratory of Neuroscience, Shanghai Institutes for Biological Sciences, Chinese Academy of Sciences, Shanghai \\ 200031, China, and 2Division of Neurobiology, Department of Molecular and Cell Biology, Helen Wills Neuroscience Institute, University of California, \\ Berkeley, California 94720
}

\begin{abstract}
Homeostatic regulation of synaptic strength in response to persistent changes of neuronal activity plays an important role in maintaining the overall level of circuit activity within a normal range. Absence of miniature EPSCs (mEPSCs) for a few hours is known to cause upregulation of excitatory synaptic strength, suggesting that mEPSCs contribute to the maintenance of excitatory synaptic functions. In the present study, we found that the absence of mEPSCs for 1-3 h also resulted in homeostatic suppression of presynaptic functions of inhibitory synapses in acute cortical slices from juvenile rats, as suggested by the reduced frequency (but not amplitude) of miniature IPSCs (mIPSCs) as well as the reduced amplitude of IPSCs. This homeostatic regulation depended on endocannabinoid (eCB) signaling, because blockade of either the activation of cannabinoid type-1 receptors (CB1Rs) or the synthesis of its endogenous ligand 2-arachidonoylglycerol (2-AG) abolished the suppression of inhibitory synapses caused by the absence of mEPSCs. Blockade of group I metabotropic glutamate receptors (mGluR-I) also abolished the suppression of inhibitory synapses, consistent with the mGluR-I requirement for eCB synthesis and release in cortical synapses. Furthermore, this homeostatic regulation also required eukaryotic elongation factor-2 (eEF2)-dependent protein synthesis, but not gene transcription. Activation of eEF2 alone was sufficient to suppress the mIPSC frequency, an effect abolished by inhibiting CB1Rs. Thus, mEPSCs contribute to the maintenance of inhibitory synaptic function and the absence of mEPSCs results in presynaptic suppression of inhibitory synapses via protein synthesis-dependent elevation of eCB signaling.
\end{abstract}

\section{Introduction}

Homeostatic regulation of synaptic strength in response to perturbation of neuronal activity plays an important role in the stabilization of neural circuit functions. Chronic blockade of action potentials (APs) for 1-2 d in neuronal cultures induced a variety of homeostatic responses, including enhanced intrinsic neuronal excitability (Marder and Prinz, 2003; Zhang and Linden, 2003), increased presynaptic glutamate secretion (Murthy et al., 2001; Burrone et al., 2002; Thiagarajan et al., 2005; Wierenga et al., 2006), elevated postsynaptic glutamate receptors (O'Brien et al., 1998; Turrigiano et al., 1998), and reduced postsynaptic $\mathrm{GABA}_{\mathrm{A}}$ receptors (Kilman et al., 2002). These neuronal and synaptic changes help to restore the circuit activity back to the normal range.

In addition to AP-associated activities, miniature excitatory synaptic activities also contribute to homeostatic regulation of excitatory synapses. Sutton et al. (2006) found that mEPSCs sup-

Received April 9, 2009; revised Aug. 24, 2009; accepted Sept. 15, 2009.

This work was supported by a grant from the National Basic Research Program of China (2006CB806600). M.-m.P. was supported in part by the United States National Institutes of Health.

*S.-y.Z. and M.X. contributed equally to this work.

Correspondence should be addressed to either of the following: Mu-ming P0o, Department of Molecular and Cell Biology, University of California, Berkeley, CA 94720-3200, E-mail:mpoo@berkeley.edu; or Xiao-hui Zhang, Institute of Neuroscience, Chinese Academy of Sciences, Shanghai 200031, China. E-mail: xhzhang@ion.ac.cn. DOI:10.1523/JNEUROSCI.1710-09.2009

Copyright $\odot 2009$ Society for Neuroscience ～0270-6474/09/2913222-10\$15.00/0 pressed dendritic protein synthesis in hippocampal neurons, and the absence of mEPSCs for $1-3 \mathrm{~h}$ led to a protein synthesisdependent increase in the density of postsynaptic AMPA receptors (AMPARs). However, more recent studies showed that $4 \mathrm{~h}$ blockade of APs resulted in homeostatic scaling of excitatory synapses in cortical neurons through a mechanism involving gene transcription, whereas selectively blocking a subset of excitatory synapses did not induce scaling of blocked synapses (Ibata et al., 2008). Thus, whether synaptic activities (including miniature events) are relevant for homeostatic regulation of synaptic efficacy remains to be clarified.

Most previous studies of homeostatic synaptic regulation were performed in cultures of dissociated neurons. More recent studies have begun to address similar regulation in acute and cultured brain slices (Sutton et al., 2006; Aoto et al., 2008; Kim and Tsien, 2008; Seeburg and Sheng, 2008). Moreover, the effects of manipulating sensory activities in vivo on homeostatic synaptic regulation have been examined in the primary visual cortex (Desai et al., 2002; Maffei et al., 2004, 2006; Maffei and Turrigiano, 2008). In the present study, we have examined the role of miniature synaptic currents (mEPSCs and mIPSCs) in homeostatic regulation of excitatory or inhibitory synapses in acute rat cortical slices. We discovered a novel form of "heterosynaptic" homeostatic regulation-the absence of mEPSCs for 1-3 h led to presynaptic suppression of inhibitory synapses, as suggested by the reduction in the MIPSC frequency. This homeostatic regula- 
tion between miniature excitatory and inhibitory synaptic activities is asymmetric, because the absence or elevation of the mIPSCs for 1-3 h had no effect on mEPSCs. Further studies showed that the reduction of the mIPSC frequency resulting from the absence of mEPSCs required the activation of endocannabinoid (eCB) signaling, in a manner that depended on both mGluR-I activation and protein synthesis but not on gene transcription. These results demonstrate the importance of miniature excitatory synaptic events in maintaining the efficacy of inhibitory synapses, and suggest a mechanism for homeostatic interaction between excitatory and inhibitory synapses over a period of a few hours.

\section{Materials and Methods}

Slice preparation. Sprague Dawley rats (postnatal days 12-15) were anesthetized with sodium pentobarbital (Nembutal, Abbott, $50 \mathrm{mg} / \mathrm{kg}$, i.p.). After decapitation, the brain was dissected rapidly and placed in ice-cold oxygenated artificial CSF (aCSF) containing the following (in mM): 125 $\mathrm{NaCl}, 3 \mathrm{KCl}, 2 \mathrm{CaCl}_{2}, 2 \mathrm{MgSO}_{4}, 1.25 \mathrm{NaH}_{2} \mathrm{PO}_{4}, 1.3 \mathrm{Na}^{+}$-ascorbate, 0.6 $\mathrm{Na}^{+}$-pyruvate, $26 \mathrm{NaHCO}_{3}$, and 10 glucose, $\mathrm{pH}$ 7.4. Coronal section of primary auditory cortex (A1) was made with a Vibratome (Vibratome), and slices (350 $\mu \mathrm{m}$ thick) were maintained in an incubation chamber with oxygenated aCSF for at least $1 \mathrm{~h}$ and then treated with different drugs (e.g., CNQX, D-AP5, and tetrodotoxin) for $1-3 \mathrm{~h}$ at $32^{\circ} \mathrm{C}$ before being transferred to the recording chamber. The care and use of rats followed the Animal Use Guideline of Shanghai Institutes for Biological Sciences, Chinese Academy of Sciences.

Recording of miniature postsynaptic currents. The treated slices were washed with continuous perfusion of oxygenated aCSF in the recording chamber for $5 \mathrm{~min}$ before recording. Whole-cell voltage-clamp recording was made from layer II/III pyramidal cells (PCs) in A1 with an Axopatch-700B amplifier (Molecular Devices), under an Olympus microscope (BX51WI) equipped with an infrared video camera and differential interference contrast optics. Miniature IPSCs (mIPSCs) were recorded at $-75 \mathrm{mV}$ in the presence of tetrodotoxin (TTX, $3 \mu \mathrm{M}$ ) and CNQX $(10 \mu \mathrm{M})$ in aCSF, while spontaneous IPSCs (sIPSCs) were recorded in the presence of CNQX $(10 \mu \mathrm{M})$ and D-AP5 $(50 \mu \mathrm{M})$. The recording pipette was filled with an internal solution containing (in $\mathrm{mM}$ ) $25 \mathrm{~K}^{+}$-gluconate, $140 \mathrm{KCl}, 10 \mathrm{HEPES}, 0.3 \mathrm{EGTA}, 4 \mathrm{Mg}$-ATP, 0.3 $\mathrm{Na}_{2} \mathrm{GTP}$, and $10 \mathrm{Na}_{2}{ }^{+}$-phosphocreatine, pH 7.3 (320-340 mOsm), and the pipette resistance was in the range of $1.4-2.2 \mathrm{M} \Omega$. Decreasing intracellular $\mathrm{Cl}^{-}$concentration to $30 \mathrm{~mm}$ caused no change in the response to the treatment with aCSF solution containing $3 \mu \mathrm{M}$ TTX, $10 \mu \mathrm{M}$ CNQX, and $50 \mu \mathrm{M}$ D-AP5 (short for "TCA" solution) for 1 or $3 \mathrm{~h}$ (supplemental Fig. S1, available at www.jneurosci.org as supplemental material). Miniature EPSCs (mEPSCs) were recorded at $-75 \mathrm{mV}$ in the presence of TTX $(3 \mu \mathrm{M})$ and bicuculline $(20 \mu \mathrm{M})$ in aCSF, and the recording pipette was filled with an internal solution containing (in $\mathrm{mm}$ ) $135 \mathrm{~K}^{+}$gluconate, $15 \mathrm{KCl}, 10 \mathrm{HEPES}, 0.3 \mathrm{EGTA}, 4 \mathrm{Mg}$-ATP, $0.3 \mathrm{Na}_{2} \mathrm{GTP}$, and 10 $\mathrm{Na}_{2}{ }^{+}$-phosphocreatine, $\mathrm{pH} 7.3$ (290-300 mOsm), and the pipette resistance was in the range of 2-3 M $\Omega$. Synaptic currents were filtered at $1 \mathrm{kHz}$ (low pass), digitized (Digidata 1322A, Molecular Devices), and acquired by the pClamp software (Molecular Devices) with a computer. From each slice, three to five cells were obtained during a $1 \mathrm{~h}$ recording period. Criteria for accepting the recorded data: resting membrane potential $\left(V_{\mathrm{m}}\right)$ of at least $-60 \mathrm{mV}$, series resistance $\left(R_{\mathrm{s}}\right)<15 \mathrm{M} \Omega$, input resistance $\left(R_{\text {in }}\right) \geq 100 \mathrm{M} \Omega$, and $<20 \%$ change in these parameters in the course of recording. For mIPSC recording (in control experiments), $R_{\text {in }}=174.7 \pm$ $2.3 \mathrm{M} \Omega, R_{\mathrm{s}}=8.5 \pm 0.1 \mathrm{M} \Omega$, and whole-cell capacitance of $117.6 \pm 0.9 \mathrm{pF}$ ( $n=344)$; for mEPSC recording (in control experiments), average $R_{\text {in }}=$ $186.7 \pm 3.9 \mathrm{M} \Omega, R_{\mathrm{s}}=11.6 \pm 0.1 \mathrm{M} \Omega$, and whole-cell capacitance of $122.9 \pm 1.5 \mathrm{pF}(n=124)$. We did not observe any significant change in the intrinsic neuronal properties induced by pharmacological treatment over the period of $1-3 \mathrm{~h}$. All recording experiments were done at $30-32^{\circ} \mathrm{C}$. MiniAnalysis and in-house software were used for the analysis of the frequency, amplitude, and kinetics of mIPSCs, sIPSCs, and mEPSCs.

Recording of evoked unitary IPSCs. Dual whole-cell recordings were made from an interneuron (in the current-clamp mode) and its targeted
PC (in the voltage-clamp mode) in layer $2 / 3$ of the rat auditory cortical slices. The recording condition and procedure were the same as that described above for recording of mIPSCs except that the low concentration of $\mathrm{Cl}^{-}$was used in the internal solution to achieve stable paired whole-cell recording (for up to $1 \mathrm{~h}$ ). The internal solution contained (in mM) $120 \mathrm{~K}^{+}$-gluconate, $30 \mathrm{KCl}, 10$ HEPES, 0.3 EGTA, $4 \mathrm{Mg}$-ATP, 0.3 $\mathrm{Na}_{2} \mathrm{GTP}$, and $10 \mathrm{Na}_{2}{ }^{+}$-phosphocreatine, pH 7.3 (290-300 mOsm), and the pipette resistance was in the range of 2-4 M $\Omega$. Interneurons were identified visually in slices, and their subtype identity was further characterized electrophysiologically by their firing behaviors as described previously (Lu et al., 2007). The cannabinoid sensitivity of recorded interneurons was determined by the existence of the postsynaptic depolarization-induced suppression of inhibition (DSI), which is mediated by retrograde eCB signaling (Ohno-Shosaku et al., 2001; Wilson and Nicoll, 2001). The DSI was examined by measuring IPSCs (at $0.4 \mathrm{~Hz}$ ) before and after voltage-clamping the postsynaptic pyramidal cell at 0 $\mathrm{mV}$ for $5 \mathrm{~s}$. This protocol was repeated at least three times. Those presynaptic interneurons exhibiting DSI were regarded as CB1R-positive neurons. To assay the properties of short-term plasticity and the coefficient of variation (CV) of unitary IPSCs, a train of 5 pulses at $20 \mathrm{~Hz}$ was applied to the presynaptic interneuron and repeated with $20 \mathrm{~s}$ intervals. The amplitudes of the first IPSC elicited by the train were used for determining CV. Transmission failures were identified visually and were included in the calculation of the mean IPSCs and CV of unitary IPSCs as events with the amplitude of $0 \mathrm{pA}$.

Data analysis. Data were presented as mean \pm SEM unless stated otherwise; $t$ test and Kolmogorov-Smirnov test were used for betweengroup comparisons. A total of 170 rats were used in the present study, and the data for each treatment condition were collected from slices obtained from at least 3 rats.

Source of materials. Anisomycin, rapamycin, and URB532 were purchased from Calbiochem, TTX was from Institute of Hydrobiology (Wuhan, China), actinomycin D was from Amresco, JZL184 was from Cayman Chemical, and CNQX, D-AP5, and AM251 were from Tocris Bioscience. All other chemicals were from Sigma.

\section{Results}

\section{Absence of mEPSCs leads to reduction of mIPSC frequency}

To investigate the role of miniature excitatory synaptic events on homeostatic regulation of excitatory and inhibitory synapses, we performed whole-cell recordings on layer $2 / 3$ pyramidal cells in acute slices of the primary auditory cortex obtained from juvenile rats (P12-P15). In the presence of TTX $(3 \mu \mathrm{M})$, mEPSCs and mIPSCs were recorded by additional application of bicuculline $(20 \mu \mathrm{M})$ and CNQX $(10 \mu \mathrm{M})$, respectively. We found that 1 or $3 \mathrm{~h}$ incubation of the slices with the NMDA receptor (NMDAR) antagonist D-AP5 $(50 \mu \mathrm{M})$ and TTX $(3 \mu \mathrm{M})$, which blocked NMDAR-mediated component of mEPSCs, led to an elevated amplitude and frequency of mEPSCs (supplemental Fig. S2, available at www.jneurosci.org as supplemental material). These results agree in part with those found in hippocampal neurons after similar blockade of excitatory synaptic activities for a few hours (Sutton et al., 2006, see Discussion).

To further examine the role of mEPSCs in homeostatic regulation of inhibitory synapses, we incubated the slices for $1-3 \mathrm{~h}$ with a solution containing the TTX $(3 \mu \mathrm{M})$, CNQX $(10 \mu \mathrm{M})$, and D-AP5 $(50 \mu \mathrm{M})$, a treatment hereafter referred to as "TCA." We found that this treatment resulted in a reduction of the frequency but not the amplitude of mIPSCs (Fig. $1 A, C$ ). In contrast, mIPSCs were not affected in slices treated with TTX alone for $3 \mathrm{~h}$ (Fig. $1 B, C$ ) or with aCSF for up to $5 \mathrm{~h}$ (Fig. $1 C$ ), indicating that blockade of APs and AP-evoked synaptic events was not sufficient to induce the suppression of the mIPSC frequency. Comparison with the results of TCA treatment indicates that the absence of mEPSCs over 1-3 $h$ was responsible for the reduction of the mIPSC frequency. 
Although blocking APs for $3 \mathrm{~h}$ did not induce the suppression of the MIPSC frequency, APs and associated synaptic events may still contribute in part to the maintenance of normal inhibitory synaptic activity. This is suggested by the finding that in the absence of TTX, the effect of CNQX $(10 \mu \mathrm{M})$ and D-AP5 $(50 \mu \mathrm{M})$ in suppressing mIPSC frequency exhibited a slower time course, detectable only after $3 \mathrm{~h}$ treatment (Fig. 1C). Furthermore, we found that $3 \mathrm{~h}$ treatment with TTX $(3 \mu \mathrm{M})$ together with either CNQX $(10 \mu \mathrm{M})$ or D-AP5 $(50 \mu \mathrm{M})$ alone led to a similar but partial suppression of the MIPSC frequency (supplemental Fig. S3, available at www.jneurosci.org as supplemental material), indicating that the absence of either the AMPAR or the NMDAR component of mEPSCs is sufficient to cause the suppression of the MIPSC frequency. Together, these results suggest that mEPSC activity is involved in regulating inhibitory synaptic activity.

To investigate whether the absence of mEPSCs also induces suppression of inhibitory synapses in other brain regions, we examined the effects of blocking mEPSCs on inhibitory synapses onto pyramidal cells in layer $2 / 3$ of primary visual cortical slices and in the CA1 area of the hippocampal slices. We found that $3 \mathrm{~h}$ treatment with TTX $(3 \mu \mathrm{M})$ and CNQX $(10 \mu \mathrm{M})$ resulted in a significant reduction in the frequency but not the amplitude of mIPSCs in the visual cortex, similar to that described above for the auditory cortex. However, the same treatment had no significant effect on mIPSCs in the CA1 hippocampal pyramidal cells (supplemental Fig. S4, available at www.jneurosci.org as supplemental material). Thus, the suppression of inhibitory synapses induced by the absence of mEPSCs appeared to be cortex-specific phenomenon.

\section{Alteration of mIPSC activity has no effect on mEPSCs}

If changes in mEPSCs contribute to homeostatic regulation of mIPSCs, does alteration of mIPSCs also induce changes in mEPSCs? We further examined the existence of such reciprocal regulation in acute cortical slices. We found that treatment with bicuculline $(20 \mu \mathrm{M})$ or diazepam $(5 \mu \mathrm{M})$, which inhibits or enhances $\mathrm{GABA}_{\mathrm{A}}$ receptor activity, for $3 \mathrm{~h}$ in the presence of TTX ( 3 $\mu \mathrm{M})$ did not result in any significant change in either the frequency or the amplitude of mEPSCs (Fig. 2), suggesting that alteration of mIPSCs has no effect on mEPSCs. However, in the absence of TTX, treatment with bicuculline (for 1 or $3 \mathrm{~h}$ ) led to a significant reduction in the amplitude but not the frequency of mEPSCs (Fig. 2C), whereas treatment with diazepam (for 1 or $3 \mathrm{~h}$ ) increased the frequency but not the amplitude of mEPSCs (Fig. 2C). These bicuculline and diazepam effects (in the absence of TTX) may be attributed to the alteration of overall circuit activities (including both APs and synaptic activities) due to the removal and enhancement of inhibition, respectively. Thus, we did not find any direct reciprocal regulation of mEPSCs due to
B TTX
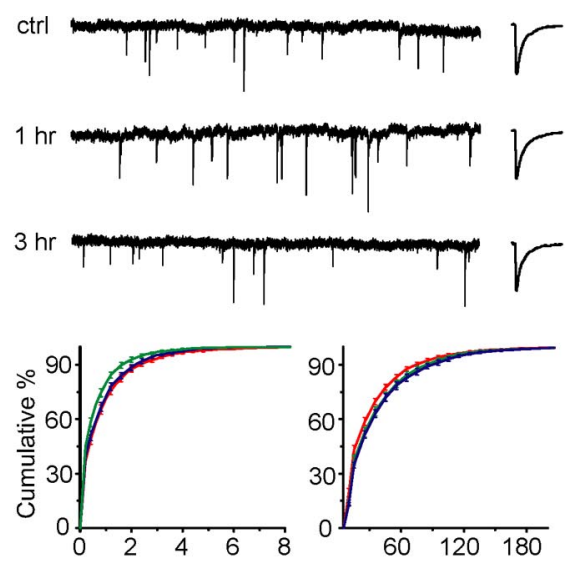

Inter-mIPSC interval (s) mIPSC Amplitude (pA)
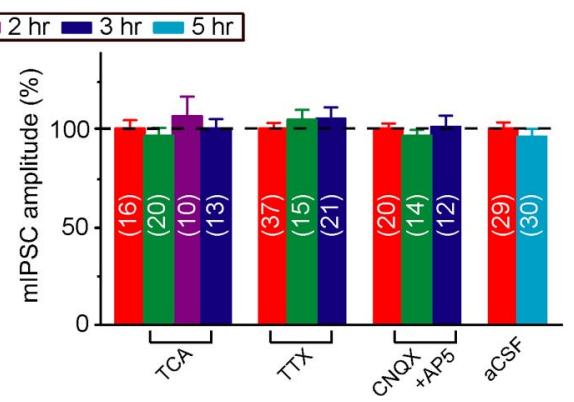

Figure 1. Effects of blocking mEPSCs and APs on mIPSCS. A, Effects of 1 or 3 h treatment with TTX, CNQX, and D-AP5 (TCA). Traces (right), normalized by those obtained from control slices (treated with a(SF). Data include of cells recorded. Error bars indicate SEM. Data significantly different from control are marked by asterisks $\left({ }^{*} p<0.05,{ }^{* *} p<0.01\right.$, ${ }^{* * *} p<0.001 ; t$ test; relative to controls). ctrl, Control.

alteration in mIPSCs for $1-3 \mathrm{~h}$, although changes in the inhibitory activity could result in homeostatic regulation of excitatory synapses indirectly via alteration of the global circuit activity. Finally, we noted that blocking APs with TTX alone for $1-4 \mathrm{~h}$ had no effect on mEPSCs (Fig. 2C), again indicating the importance of miniature excitatory synaptic activities in homeostatic regulation over a period of a few hours.

\section{Suppression of mIPSCs requires eCB signaling}

The reduction in the frequency but not the amplitude of mIPSCs due to the absence of mEPSCs suggests presynaptic suppression of GABA release. Endocannabinoids (eCBs) are lipid molecules known to mediate short-term retrograde suppression of inhibitory synapses caused by postsynaptic depolarization (OhnoShosaku et al., 2001; Wilson and Nicoll, 2001). Furthermore, eCBs selectively reduced the frequency but not the amplitude of mIPSCs in cerebellar Purkinje cells as well as hippocampal and neocortical pyramidal cells, via retrograde activation of cannabinoid type 1 receptors (CB1Rs) on presynaptic nerve terminals (Schlicker and Kathmann, 2001; Wilson and Nicoll, 2001; Trettel and Levine, 2002; Diana and Marty, 2003; Freund et al., 2003). Thus, we examined whether eCB signaling also mediates the persistent reduction of the mIPSC frequency induced by the absence 
A

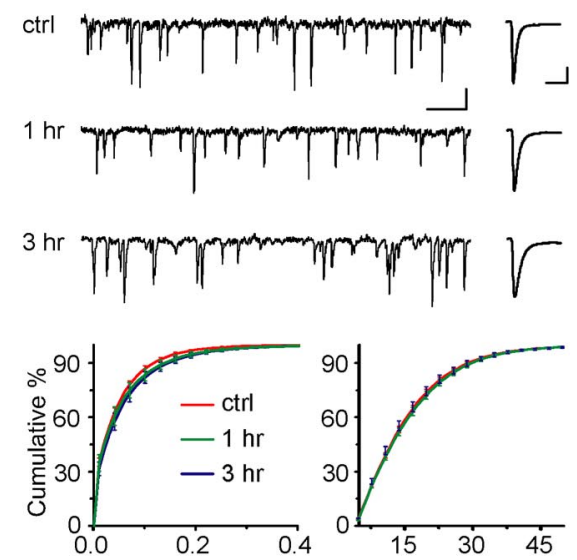

Inter-mEPSC interval (s) mEPSC Amplitude (pA)
B
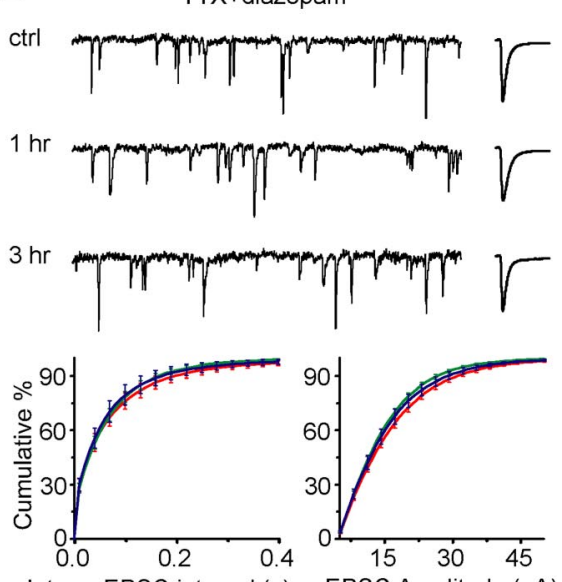

Inter-mEPSC interval (s) mEPSC Amplitude (pA)

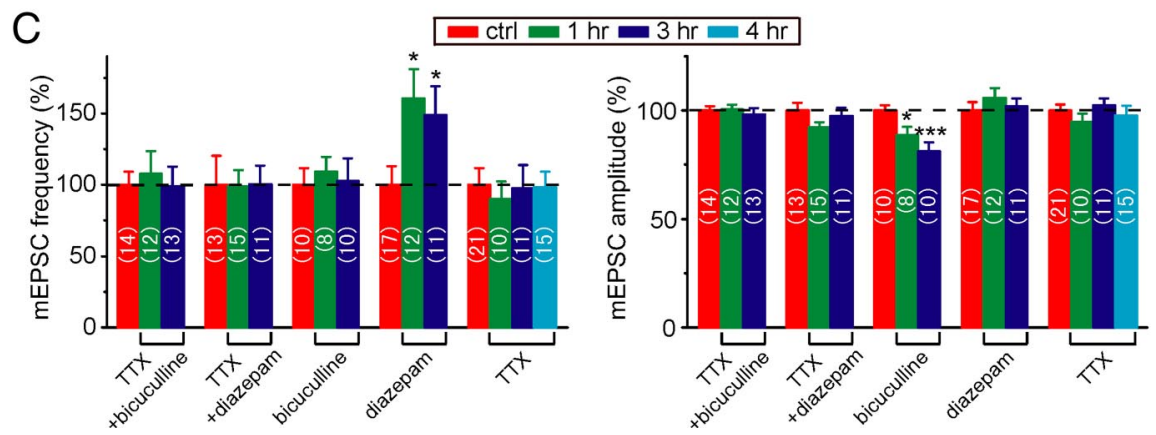

Figure 2. Effects of blocking or enhancing mIPSCs on mEPSCS. $A$, Effects of 1 or $3 \mathrm{~h}$ treatment with bicuculline and TTX. Traces above depict sample whole-cell recording of membrane currents (at $V_{c}=-75 \mathrm{mV}$ ) and an averaged trace of mEPSCs recorded over $1 \mathrm{~s}$ duration. Calibrations: 10 pA, 100 ms; 5 pA, $10 \mathrm{~ms}$ (for averaged mEPSCs). Bottom, Cumulative percentage plot of interevent intervals for mEPSCs (left) and mEPSC amplitude (right). Data points represent average values (for $0.03 \mathrm{~s}$ and $3 \mathrm{pA}$ bins, respectively) of all neurons recorded for the same treatment. $\boldsymbol{B}$, Similar to $\boldsymbol{A}$, except that the slices were treated with diazepam and TTX for 1 or $3 \mathrm{~h}$. C, Average values of mEPSC frequency (left) and amplitude (right), normalized by those obtained from control slices treated with aCSF. Data include those from experiments in $\boldsymbol{A}$ and $\boldsymbol{B}$ and slices treated with bicuculline alone or diazepam alone for 1 or $3 \mathrm{~h}$, as well as slices treated with TTX alone for $1-4 \mathrm{~h}$. Error bars indicate SEM $\left({ }^{*} p<0.05\right.$ and ${ }^{* * *} p<0.001$; $t$ test; relative to controls). ctrl, Control.

of mEPSCs. As shown in Figure 3A, we found that the presence of the selective CB1R antagonist AM251 ( $5 \mu \mathrm{M})$ prevented the reduction of the MIPSC frequency induced by 1 or $3 \mathrm{~h}$ treatment with TCA. Furthermore, activation of CB1R appears to be required only for inducing but not for maintaining the suppression of mIPSCs, because we found that after $1 \mathrm{~h}$ TCA treatment, further blockade of CB1R with one additional hour of AM251 treatment (in the presence of TCA) did not affect the suppressed mIPSCs (Fig. 3C). That the AM251 treatment alone had no effect on mIPSCs may be attributed to the on-demand synthesis and release of eCBs (Piomelli, 2003). In all above experiments, no change in the mIPSC amplitude was observed (Fig. 3D; supplemental Fig. S5, available at www.jneurosci.org as supplemental material). Thus, CB1R activation is responsible for the initiation but not the maintenance of the homeostatic suppression of inhibitory synapses, similar to its requirement for long-term depression (LTD) of inhibitory synapses on hippocampal CA1 pyramidal cells (Chevaleyre and Castillo, 2003), and excitatory synapses on cortical pyramidal cells (Sjöström et al., 2003) and striatal medium spiny cells (Ronesi et al., 2004).

Several endogenous ligands for CB1Rs in the brain have been identified (Piomelli, 2003). We have examined the potential involvement of the two best characterized eCBs, $\mathrm{N}$-arachidonoylethanolamide (AEA) and 2-arachidonoylglycerol synapses.
(2-AG) (Chevaleyre et al., 2006), in the homeostatic suppression of mIPSCs resulting from the absence of mEPSCs. Reducing 2-AG synthesis by bath application of the diacylglycerol lipase inhibitor RHC80267 $(30 \mu \mathrm{M})$ or lipase inhibitor tetrahydrolipstatin (THL, $5 \mu \mathrm{M}$ ) during the 1-3 h TCA treatment completely prevented the reduction of the MIPSC frequency (Fig. 3A). Furthermore, elevating the 2-AG level by inhibiting its hydrolysis with monoacylglycerol lipase (MAGL) inhibitor JZL184 (80 nM) facilitated the reduction of mIPSC frequency during TCA treatment, whereas elevating the AEA level by inhibiting its hydrolysis with fatty acid amide hydrolases 1 (FAAH1) inhibitor URB532 $(10 \mu \mathrm{M})$ had no effect on TCA-induced mIPSC suppression (Fig. $3 A$ ). In separate experiments, we found that treatment with RHC80267, THL, JZL184, or URB532 for 1 or $3 \mathrm{~h}$ all had no effect on the frequency of mIPSCs (Fig. $3 B)$. In all of the above experiments, the mean mIPSC amplitude was not affected (supplemental Fig. S5, available at www. jneurosci.org as supplemental material). Thus, we identified 2-AG rather than AEA as the $\mathrm{eCB}$ responsible for mediating the homeostatic suppression of mIPSCs in these cortical neurons.

Previous studies have shown that activation of mGluR-I is sufficient to trigger eCB release (Varma et al., 2001; OhnoShosaku et al., 2002, 2003; Fukudome et al., 2004). Furthermore, the enzyme for 2-AG synthesis, DAGL- $\alpha$, is anchored together with mGluR-I into a macromolecular complex via the coiled-coil (CC)Homer proteins (Jung et al., 2007; Katona and Freund, 2008). We found that the presence of the mGluR-I antagonist $(+) \alpha$-methyl4-carboxyphenylglycine (MCPG, $250 \mu \mathrm{M}$ ) indeed prevented the reduction of the mIPSC frequency under 1-3 h TCA treatment (Fig. 4), whereas treatment with MCPG alone for the same duration had no effect. Thus, mGluR-I activation is required for the eCB-dependent homeostatic regulation of cortical inhibitory

\section{Suppression of AP-evoked IPSCs also requires \\ CB1R activation}

In addition to mIPSCs, we also examined homeostatic suppression of spontaneous IPSCs (sIPSCs), which consist of both mIPSCs and AP-evoked IPSCs. We found that treatment with CNQX $(10 \mu \mathrm{M})$ and D-AP5 $(50 \mu \mathrm{M})$ for $3 \mathrm{~h}$ resulted in a significant reduction in both the mean frequency and amplitude of sIPSCs (Fig. 5C,D), in addition to the suppression of the mean mIPSC frequency (Fig. $5 A, B)$. Relative to their respective control values, the extent of reduction of the sIPSC frequency (46\%) was higher than that of mIPSC frequency $(37 \%)$, suggesting that the IPSC frequency must also be reduced. This implicates the reduction of AP generation and/or the transmitter release probability in presynaptic inhibitory nerve terminals. Meanwhile, since the mIPSC amplitude was not affected, the reduction in the mean sIPSC amplitude 
must be attributed to the decreased amplitude (or the "quantal content") of IPSCs. Moreover, the presence of the selective CB1R antagonist AM251 completely abolished the changes in both sIPSCs and mIPSCs resulting from the $3 \mathrm{~h}$ treatment with CNQX and D-AP5 (Fig. 5B,D), suggesting similar mechanisms underlying the suppression of mIPSCs and IPSCs.

We further examined the reduction of IPSCs by performing paired recording from an interneuron and its target $\mathrm{PC}$ in layer $2 / 3$ of the A1. Since CB1Rs are selectively expressed in a subgroup of interneurons (Piomelli, 2003; Freund and Katona, 2007), we mainly focused on two distinct classes of layer $2 / 3$ neocortical interneurons, fast-spiking (FS) and low-threshold-spiking (LTS) cells, which are CB1R-negative and -positive interneurons, respectively (Bacci et al., 2004; Lu et al., 2007). In the present study, we first identified FS and LTS cells in layer 2/3 of A1 using criteria described previously (Lu et al., 2007) (supplemental Fig. S6, available at www.jneurosci.org as supplemental material), and then examined whether DSI (see Materials and Methods), which is known to depend on presynaptic CB1Rs, could be induced at FS-PC and LTS-PC synapses. As shown by example cases in Figure $6,5 \mathrm{~s}$ depolarization (to $0 \mathrm{mV}$ ) induced no change in IPSCs in FS-PC synapses (Fig. 6A), but transient reduction of IPSC amplitude in LTS-PC synapses (Fig. 6D). Based on the membrane and spiking properties as well as neuronal morphology under IR-DIC optics, most of FS and LTS cells resembled the previous morphologically defined multipolar cells and bitufted cells, respectively (Reyes et al., 1998; Koester and Johnston, 2005). We further found that those inhibitory synapses exhibiting no DSI, mostly made by the FS cell, showed no significant difference in the short-term plasticity (as tested by a train of 5 pulses at $20 \mathrm{~Hz}$ ), the mean amplitude and the $\mathrm{CV}$ of the first IPSCs between CNQX/D-AP5-treated (for $3 \mathrm{~h}$ ) slices and control untreated slices (Fig. 6B,C). These results suggested that the treatment did not alter either presynaptic or postsynaptic properties at these inhibitory synapses originated from DSI-negative interneurons. In contrast, for LTS-PC synapses exhibiting DSI, presumably possessing presynaptic CB1Rs, we found that the CNQX/D-AP5 treatment to slices (for $3 \mathrm{~h}$ ) converted the short-term depression to the facilitation and resulted in an increased CV of the first IPSC (Fig. $6 E$ ), suggesting a reduction of presynaptic release probability. As a result, a significant reduction of the mean IPSC amplitude of LTS-PC (DSI-positive) synapses was observed in CNQX/ D-AP5-treated slices $(p=0.04$, compared to control slices, Kolmogorov-Smirnov test) (Fig. 6 F). In parallel, there was also an increase of the transmission failures rate of these GABAergic synapses in CNQX/D-AP5-treated slices $(69 \pm 9 \%$, $n=6$; SEM, compared to $41 \pm 8 \%$ in control slices; $n=5$ ). Together, these results support the notion that blockade of excitatory synaptic transmission induces homeostatic suppression of a subset of inhibitory synapses that are sensitive to $\mathrm{eCB}$ signaling, leading to downregulation of presynaptic transmitter release efficacy in these inhibitory neurons.

\section{Homeostatic suppression of mIPSCs requires protein synthesis}

The finding that three types of treatment (TCA, TTX/D-AP5, and TTX/CNQX) for $3 \mathrm{~h}$ all induced similar CB1R-dependent reduction of the frequency but not the change significantly. ctrl, Control.
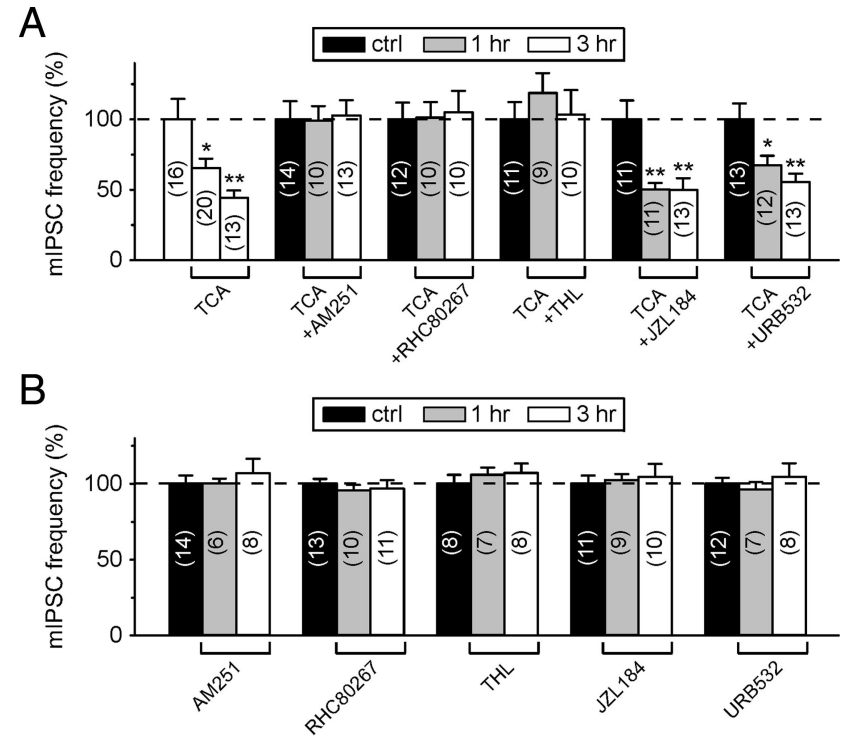

C

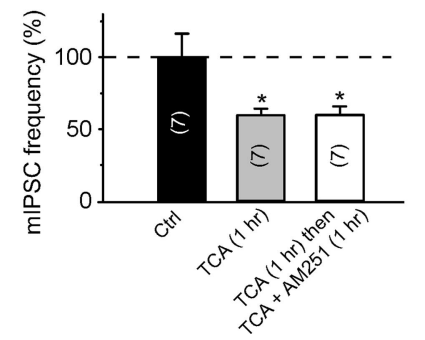

$\mathrm{D}$

Figure 3. eCB signaling is required for the reduction of mIPSC frequency. A, Average values of $\mathrm{mIPSC}$ frequency, normalized by those obtained from control slices (treated with aCSF). AM251, RHC80267, and THL completely abolished the reduction of mIPSC frequency induced by the TCA treatment for 1 or $3 \mathrm{~h}$. JZL184 facilitated and URB532 had no effect on the reduction of mIPSC frequency. The data shown with unfilled bars are the same dataset as in Figure 1C. Error bars indicate SEM $\left({ }^{*} p<0.05,{ }^{* *} p<0.01 ; t\right.$ test; relative to controls). $\boldsymbol{B}$, Similar to what was seen for $\boldsymbol{A}$, treatment with AM251, RHC80267, THL, JZL184, or URB532 alone had no effect on mIPSCS. C, D, Average values of mIPSC frequency $(\boldsymbol{C})$ and amplitude $(\boldsymbol{D})$, normalized by those obtained from control slices (treated with aCSF), from the experiments in which the slices were first treated with TCA (for $1 \mathrm{~h}$ ) and then followed by cotreatment with TCA and AM251 (for 1 additional hour). No significant change in the averaged mIPSC amplitude was observed. Error bars indicate SEM ( ${ }^{*} p<0.05 ; t$ test; relative to controls). ctrl, Control.
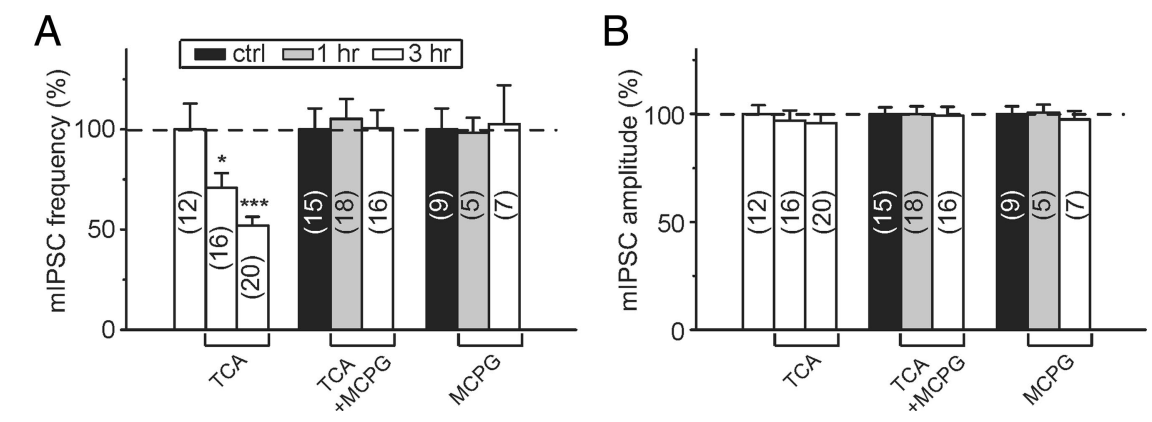

Figure 4. Activation of mGluR-I is required for the reduction of mIPSC frequency. A, Average values of mIPSC frequency, normalized by those obtained from control slices (treated with aCSF). MCPG completely abolished the reduction of mIPSC frequency induced by the TCA treatment (for 1-3 h). Treatment with MCPG alone had no effect on mIPSCs. The data shown with unfilled bars are the same dataset as in Figure 1. Error bars indicate SEM ( ${ }^{*} p<0.05,{ }^{* *} p<0.01 ; t$ test; relative to controls). $B$, Similar to $A$, except the bars depict the average mIPSC amplitude. In all these experiments, the average mIPSC amplitude did not 

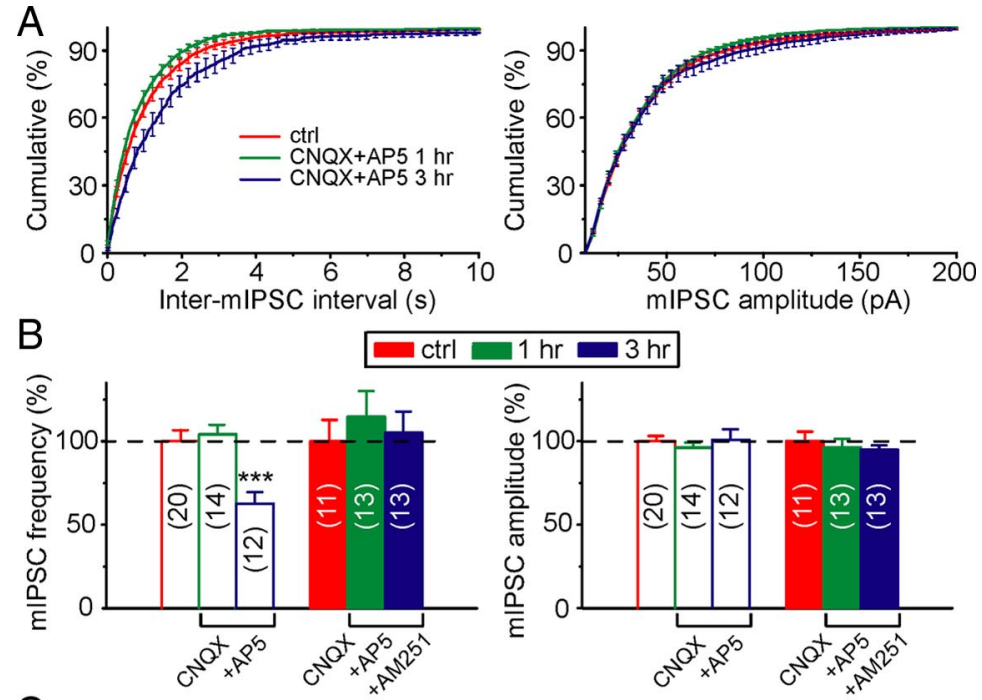

\section{C}
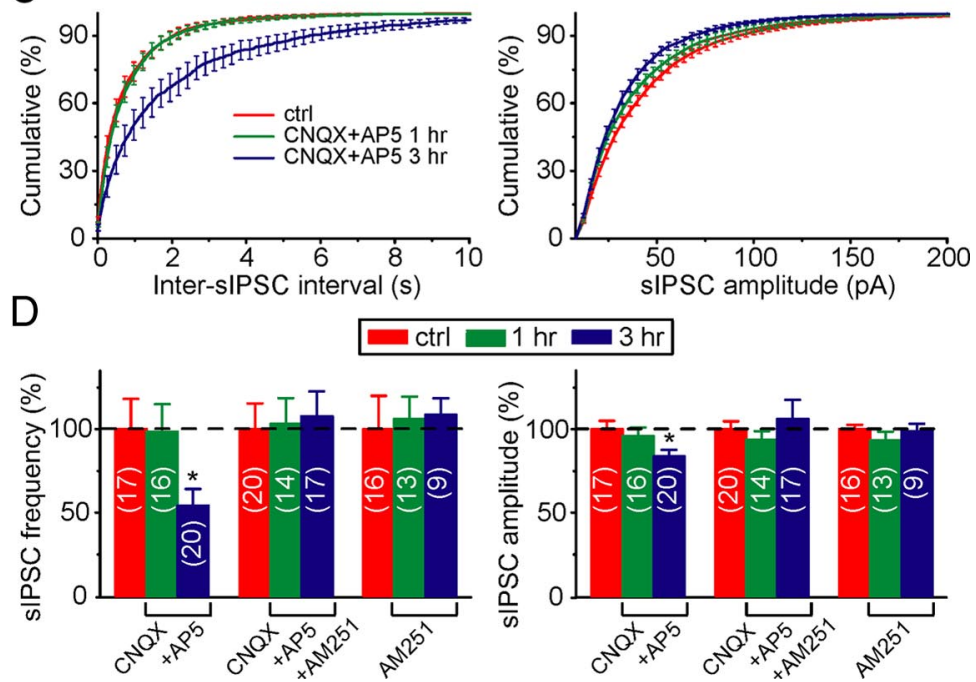

Figure 5. Absence of mEPSCs results in CB1R-dependent reduction of both frequency and amplitude of sIPSCS. A, Cumulative percentage plot of interevent intervals of mIPSCS (left) and the mIPSC amplitude (right). Data points represent average values (for $0.25 \mathrm{~s}$ and $4 \mathrm{pA}$ bins, respectively) of all neurons recorded for the same treatment ( $n$ shown in $\boldsymbol{B}$ ). Differences of mIPSC frequency between control and $3 \mathrm{~h}$ datasets were significant ( $p<0.001$, Kolmogorov-Smirnov test). $\boldsymbol{B}$, Average values of mIPSC frequency (left) and amplitude (right), normalized by those obtained from control slices treated with aCSF, following treatments with CNQX and D-AP5 (for 1 or $3 \mathrm{~h}$ ), with or without AM251. Error bars indicate SEM (***p $<0.001$; $t$ test; relative to controls). C, Similar to $A$, except that sIPSCS (consisting of mIPSCs and AP-evoked IPSCS) were recorded. Differences of sIPSC frequency and amplitude between control and $3 \mathrm{~h}$ datasets were significant ( $p<0.001$ and $p<0.01$, respectively; Kolmogorov-Smirnov test). $D$, Average values of sIPSC frequency (left) and amplitude (right), normalized by those obtained from control slices treated with aCSF, following treatments with CNQX, D-AP5 (for 1 or 3 h), with or without AM251, as well as with AM251 alone $\left({ }^{*} p<0.05\right.$; $t$ test; relative to controls). ctrl, Control.

amplitude of mIPSCs (Fig. 1C; supplemental Fig. S3, available at www.jneurosci.org as supplemental material) suggests similar underlying mechanisms. Sutton et al. $(2004,2006)$ found that blockade of the AMPAR and/or the NMDAR component of mEPSCs in cultured hippocampal neurons induced a rapid activation of protein synthesis, which in turn caused an upscaling of AMPAR-mediated mEPSCs. In this study, we found that protein synthesis inhibitor anisomycin $(30 \mu \mathrm{M})$ or cycloheximide $(60$ $\mu \mathrm{M})$ completely abolished the reduction of the mIPSC frequency induced by the 1 or $3 \mathrm{~h}$ TCA treatment (Fig. 7A), whereas treatment with either anisomycin or cycloheximide alone for the same duration had no effect (Fig. 7 A,B). Furthermore, 1-3 h treatment with the transcriptional inhibitor actinomycin D $(25 \mu \mathrm{M})$, which by itself had no effect on mIPSCs, did not prevent the reduction of the MIPSC frequency caused by the TCA treatment (Fig. 7 $A, B$ ). Together, these results indicate that protein synthesis (but not gene transcription) is required for the reduction of the MIPSC frequency induced by the absence of mEPSCs.

\section{Homeostatic suppression of mIPSCs requires eEF2 activation}

The activity of eukaryotic elongation factor-2 (eEF2), which contributes to protein synthesis, is bidirectionally regulated through its phosphorylation by changes in the mEPSC activity (Sutton et al., 2007). However, it remains unclear whether such changes in eEF2 activity are directly linked to homeostatic regulation of inhibitory synapses induced by the absence of mEPSCs. To investigate the involvement of eEF2, we used rapamycin to inhibit the mTOR (mammalian target of rapamycin) pathway, which induces eEF2 phosphorylation and inactivation (Proud, 2006). As shown in Figure $8 A$, cotreatment with rapamycin ( $250 \mathrm{~nm}$ ) completely abolished the reduction of the MIPSC frequency induced by the TCA treatment (for 1 or $3 \mathrm{~h}$ ). Interestingly, the rapamycin treatment alone caused a gradual increase in the mIPSC frequency, presumably through the suppression of the basal eEF2 activity. Moreover, treatment with either NH125 $(10 \mu \mathrm{M})$ or rottlerin $(5 \mu \mathrm{M})$, which dephosphorylates and activates eEF2 (Gschwendt et al., 1994; Arora et al., 2003), mimicked the TCA effect in reducing the mIPSC frequency and this effect was completely abolished by the CB1R antagonist AM251 (5 $\mu \mathrm{M})$ (Fig. 8B; supplemental Fig. 7, available at www.jneurosci.org as supplemental material). That the effects of TCA and NH125 are mediated by the same mechanism is further supported by the following occlusion experiments. First, treatment with TCA and NH125 together for $1 \mathrm{~h}$ caused the same extent of reduction in the MIPSC frequency as that caused by TCA or NH125 alone for $1 \mathrm{~h}$ (Fig. 8C). Second, after $1 \mathrm{~h}$ TCA treatment, further NH125 treatment alone for $1 \mathrm{~h}$ did not cause additional reduction of the mIPSC frequency (Fig. 8C). Thus, eEF2-dependent protein synthesis is required and sufficient for initiating the CB1R-mediated signaling that suppresses inhibitory synapses.

\section{Discussion}

Miniature excitatory synaptic activity may contribute to the maintenance of normal structure and function of excitatory synapses. It is involved in maintaining the density and morphology of dendritic spines in cultured CA1 pyramidal cells (McKinney et al., 1999) and required for normal postsynaptic glutamate receptor clustering at Drosophila neuromuscular junctions (Saitoe et al., 2001). At hippocampal synapses, Sutton et al. (2004, 2006) 
found that blocking NMDAR-mediated mEPSCs (in the presence of TTX) for a few hours induced a protein synthesisdependent elevation of the postsynaptic AMPA receptor density. In the present study, we found that the absence of mEPSCs for $1-3 \mathrm{~h}$ also resulted in the suppression of inhibitory synapses, as shown by the reduction in the mean frequency of mIPSCs and the mean amplitude of APevoked IPSCs. In contrast, altering the mIPSC activity for $1-3 \mathrm{~h}$ did not affect mEPSCs. Furthermore, the absence of mEPSCs triggered an eEF2-dependent protein synthesis, which in turn results in the retrograde $\mathrm{eCB}$ signaling and presynaptic suppression of GABAergic inputs. Our results underscore the physiological importance of miniature excitatory synaptic events in the maintenance of synaptic functions and delineate a cellular mechanism by which alteration in excitatory synaptic activity may regulate the efficacy of inhibitory synapses.

\section{Homeostatic presynaptic versus postsynaptic modifications}

Homeostatic synaptic scaling may involve both presynaptic and postsynaptic changes (Turrigiano, 2007, 2008). For excitatory synapses, chronic activity blockade (for 1-2 d) in cultured neurons causes an increase of both postsynaptic AMPAR density and presynaptic transmitter release (Turrigiano et al., 1998; Murthy et al., 2001; Burrone et al., 2002; Thiagarajan et al., 2005; Wierenga et al., 2005). Relatively short-term absence of mEPSCs or blockade of APs in cultured neurons (for a few hours) was shown to increase postsynaptic AMPAR density (Sutton et al., 2006; Ibata et al., 2008). Our results further demonstrate that the absence of mEPSCs for $1-3 \mathrm{~h}$ caused an increase in both the amplitude and frequency of mEPSCs in cortical pyramidal cells (supplemental Fig. S2, available at www.jneurosci.org as supplemental material), suggesting increased presynaptic transmitter release in addition to AMPAR density. Differential involvement of presynaptic and postsynaptic sites found in different studies may be attributed to differences in the experimental treatment, the preparation (slice vs dissociated cells), the extent of synapse maturation, and the synapse type under investigation. The latter is nicely illustrated by a recent study in organotypic hippocampal cultures, in which $2 \mathrm{~d}$ TTX treatment resulted in differential homeostatic presynaptic and postsynaptic changes in three sets of excitatory hippocampal synapses: dentate-to-CA3 and CA3-to-CA1 synapses were upregulated by increasing the frequency and amplitude of mEPSCs, respectively, while CA3-to-CA3 synapses were downregulated by reducing the mEPSC frequency (Kim and Tsien, 2008). Thus, excitatory synapses in the feedforward and recurrent circuits may exhibit distinct forms of homeostatic synaptic regulation.
DSI-negative

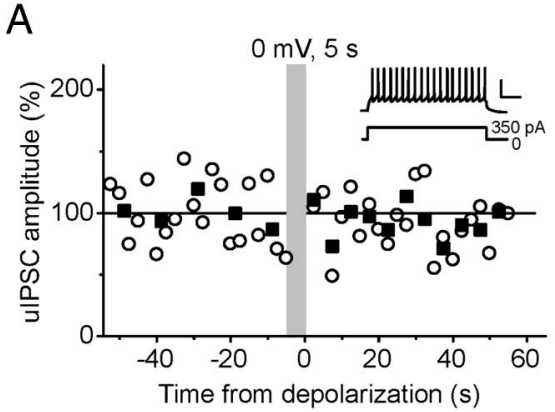

$B$
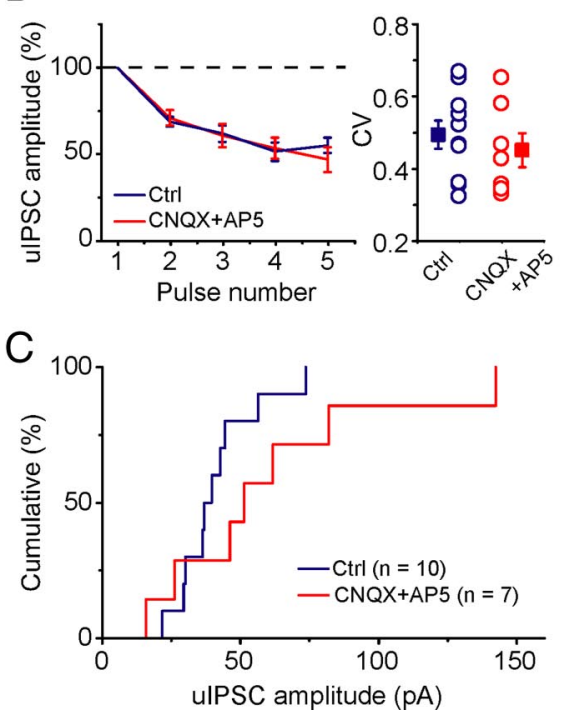

DSI-positive

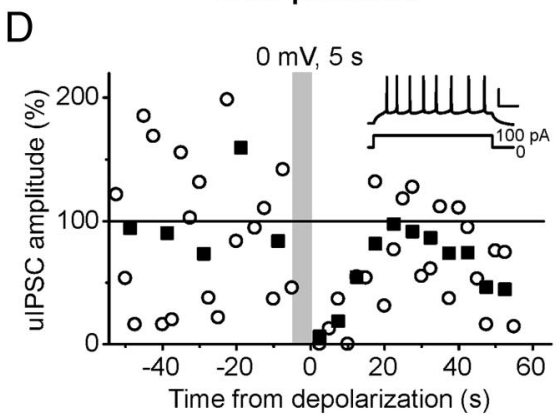

$\mathrm{E}$

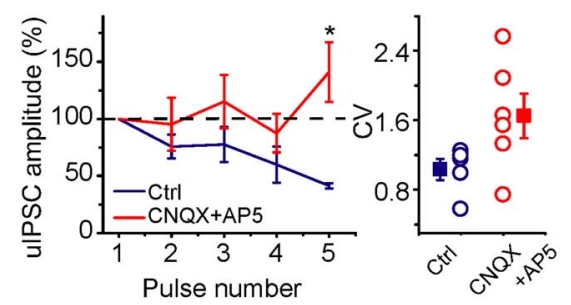

F

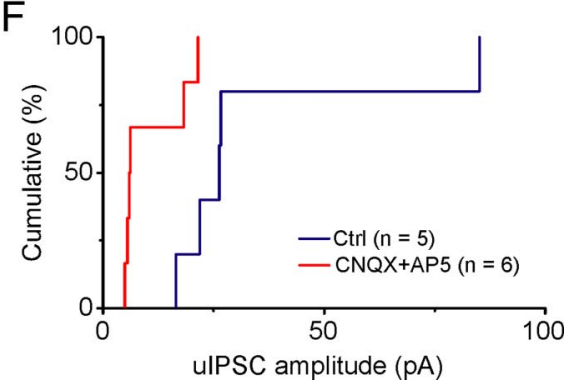

Figure 6. Changes of short-term plasticity, CV and the mean IPSC amplitude in DSI-negative and DSI-positive interneurons. $\boldsymbol{A}, \boldsymbol{D}$, representative recordings of DSI-negative $(\boldsymbol{A})$ and DSI-positive $(\boldsymbol{D})$ inhibitory synapses in layer $2 / 3$ of the $A 1$ slices. The DSI was 作 (uIPSCs, open circles) were recorded in PCs $\left(V_{c}=-70 \mathrm{mV}\right)$, and averaged for 4 and 2 IPSCs before and after DSI (filled squares), respectively. The amplitudes of uIPSCs were normalized by the mean value before the DSI. The majority of DSI-negative by a step depolarizing current. Calibration: $40 \mathrm{mV}, 80 \mathrm{~ms} . \boldsymbol{B}, \boldsymbol{E}$, The changes of short-term plasticity and CV of first IPSCS of (b) and DSI-positive $(\boldsymbol{E})$ inhibitory synapses in the control (blue circles) and CNQX/D-AP5-treated (for $3 \mathrm{~h}$, red circles) evoked IPSCs evoked by a train of 5 pulses (at $20 \mathrm{~Hz}$ ) to presynaptic FS or LTS cells. *Significant difference in the amplitude of the fifth IPSC between the treated and control conditions ( $p=0.01$; unpaired $t$ test). $\boldsymbol{C}, \boldsymbol{F}$, Distributions of unitary IPSC amplitude of DSI-negative $(\boldsymbol{C}$ ) and DSI-positive $(\boldsymbol{F})$ inhibitory synapses in the control and CNQX/D-AP5-treated slices, respectively. Significant difference was found between the treated and control conditions in DSI-positive interneurons ( $p=0.04$, Kolmogorov-Smirnov test) but not in DSI-negative interneurons $(p=0.25) . n$, Number of examined cell pairs. Ctrl, Control.

Chronic activity blockade in cultured cortical neurons is also known to cause homeostatic downregulation of inhibitory synapses by reducing the postsynaptic $\mathrm{GABA}_{\mathrm{A}}$ receptors and presynaptic GAD65 expression (Kilman et al., 2002). This study showed a reduction of the MIPSC amplitude, but did not report changes in the mIPSC frequency, as might be expected if presynaptic regulation had occurred. In the present study, we have identified the signaling pathway that links the reduction of mEPSC activity to the homeostatic suppression of presynaptic GABA release, as reflected by the reduction of both mIPSC frequency and the IPSC amplitude. Thus, both presynaptic and postsynaptic properties of inhibitory synapses are under homeostatic regulation. While only inhibitory synapses on PCs were examined here, those inhibitory synapses on inhibitory neurons may also be regulated, perhaps in a manner opposite to those on excitatory neurons to achieve homeostasis of the circuit activity. This remains to be further studied. 


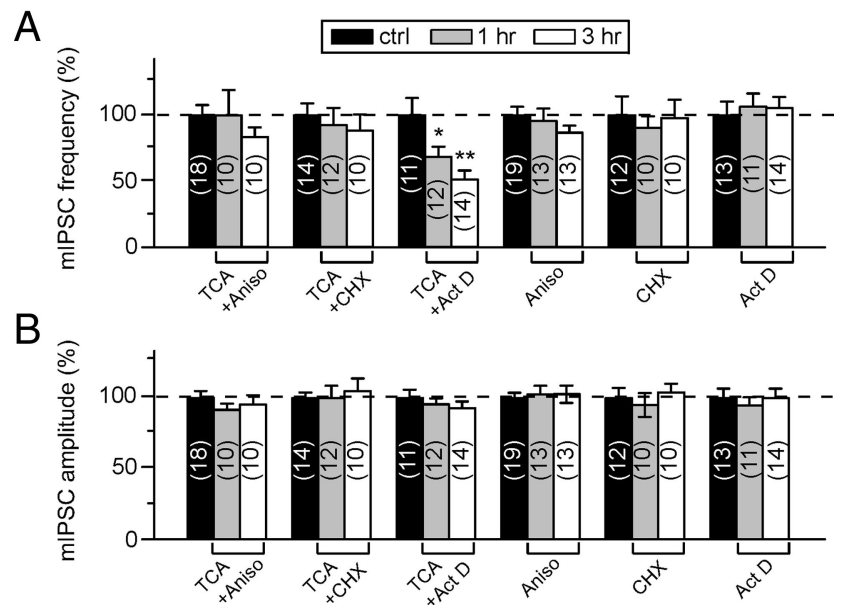

Figure 7. Protein synthesis is required for the reduction of mIPSC frequency. $\boldsymbol{A}$, Average values of the mIPSC frequency, normalized by those obtained from control slices treated with aCSF. Translation inhibitors anisomycin and cycloheximide completely abolished the reduction of mIPSC frequency induced by the absence of $\mathrm{mEPSC}$, whereas transcription inhibitor actinomycin D had no effect. Each of these drugs applied alone had no significant effect on the mIPSC frequency. Error bars indicate SEM ( ${ }^{*} p<0.05$ and ${ }^{* *} p<0.01 ; t$ test; relative to controls). $\boldsymbol{B}$, Similar to $\boldsymbol{A}$, except that the bars depict the average mIPSC amplitude. No significant change of the average mIPSC amplitude was observed in all experiments. ctrl, Control.

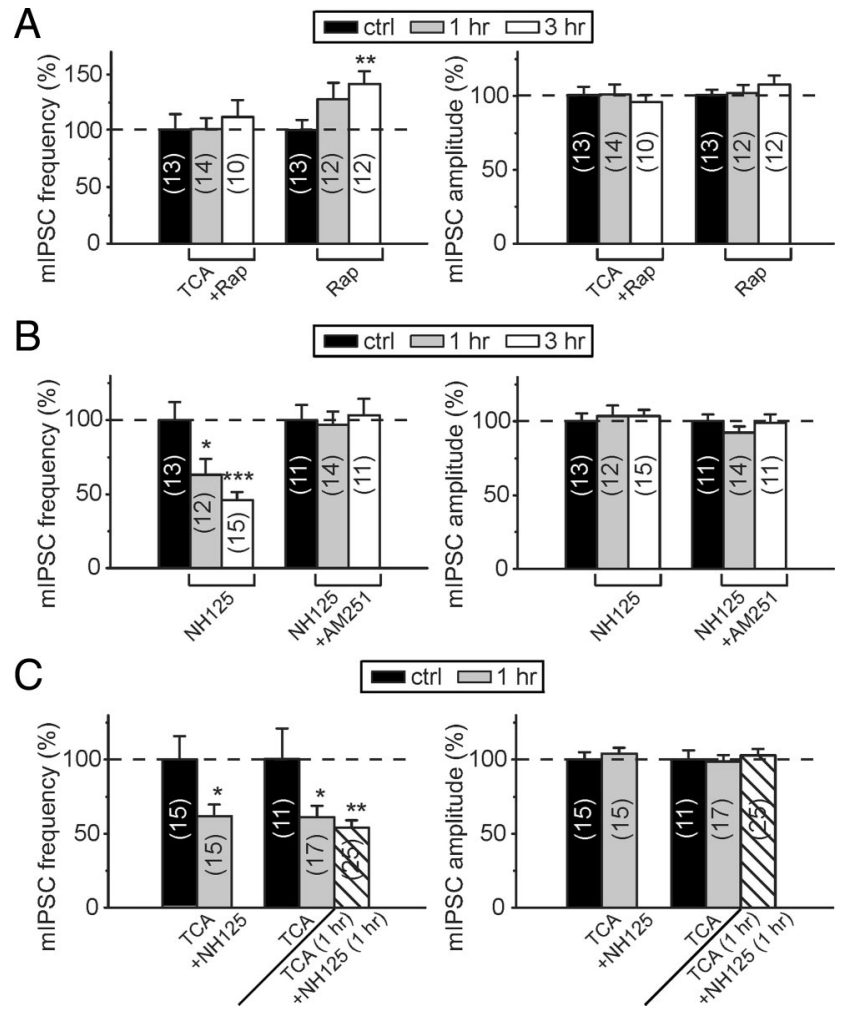

Figure 8. The eEF2-dependent protein synthesis is essential for CB1R-dependent reduction of mIPSC frequency. A, Average values of mIPSC frequency (left) and amplitude (right), normalized by those obtained from control slices treated with aCSF. Rapamycin completely abolished the reduction of mIPSC frequency induced by the absence of $\mathrm{mEPSCs}$. The treatment with rapamycin alone resulted in a time-dependent increase of mIPSC frequency. In all experiments, no change was observed in the average mIPSC amplitude. Error bars indicate SEM ${ }^{*} p<0.05$, ${ }^{* *} p<0.01$, and ${ }^{* * *} p<0.001 ; t$ test; relative to controls). $\boldsymbol{B}$, Similar to $\boldsymbol{A}$, except that the slices were treated with $\mathrm{NH} 125$ alone or together with $\mathrm{AM} 251$ for 1 or $3 \mathrm{~h}$. C, Similar to $\boldsymbol{A}$, except that the slices were treated with TCA and NH125 (for $1 \mathrm{~h}$ ), or first treated with TCA (for $1 \mathrm{~h}$ ), and then followed by $\mathrm{NH} 125$ treatment alone (for 1 additional hour). ctrl, Control.
Activity-dependent eCB signaling in homeostatic regulation Endocannabinoids (eCBs) are synthesized in neuron on demand (Piomelli, 2003) and serve as transient retrograde synaptic modulators. Postsynaptic synthesis of eCBs and their presynaptic suppressive actions account for depolarization-induced short-term depression (Kreitzer and Regehr, 2001a,b; Maejima et al., 2001; Ohno-Shosaku et al., 2001; Wilson and Nicoll, 2001) and activity-dependent LTD (Gerdeman et al., 2002; Robbe et al., 2002; Chevaleyre and Castillo, 2003; Sjöström et al., 2003; Safo and Regehr, 2005; Yin et al., 2006; Adermark and Lovinger, 2009) of both excitatory and inhibitory synapses. The present study revealed another function of the $\mathrm{eCB}$ signaling-homeostatic presynaptic regulation of inhibitory synapses in response to alteration of excitatory synaptic activities. The rapidity of its synthesis and release at the synapse and its localized retrograde actions (Wilson and Nicoll, 2001; Brown et al., 2003; Chevaleyre and Castillo, 2004; Chevaleyre et al., 2006) make eCBs ideal regulation for spatially and temporally specific homeostatic modifications. Part of the specificity of $\mathrm{eCB}$ actions may arise from the region- and cell type-specific distribution of CB1Rs (Piomelli, 2003). For example, CB1Rs densely cover cholecystokinin (CCK)positive interneuronal axon terminals but are completely absent from parvalbumin (PV)-containing cells and most other cortical and hippocampal interneurons (Freund and Katona, 2007). Given different input and output characteristics of CCK- and PV-positive interneurons (Glickfeld and Scanziani, 2006; Freund and Katona, 2007) and our results on paired recording from FS-PC and LTS-PC synapses (Fig. 6), CB1R-dependent homeostatic suppression of inhibitory synapses is likely to be pathway-specific.

The mechanisms responsible for triggering eCB release appear to be similar in both short- and long-term suppression of excitatory and inhibitory synapses-involving postsynaptic $\mathrm{Ca}^{2+}$ elevation and/or activation of mGluR-I (Chevaleyre et al., 2006). Although we found that mGluR activation is required in the eCBdependent homeostatic regulation of cortical inhibitory synapses, the link between the absence of mEPSC activity and eCB signaling remains to be fully clarified. The enhanced spontaneous glutamate release due to the 1-3 h TCA treatment, as reflected by the increased frequency and amplitude of mEPSCs, may elevate mGluR-I activation, which in turn triggers the increase of eEF2dependent protein synthesis underlying the CB1R-dependent suppression of inhibitory synapses.

\section{Role of eEF2 in homeostatic regulation}

Eukaryotic elongation factor-2 (eEF2) plays an essential role in the regulation of protein synthesis (Jørgensen et al., 2006), and can be phosphorylated (inactivated) selectively by $\mathrm{Ca}^{2+}$ / calmodulin-dependent protein kinase III (CaMKIII) (Ryazanov et al., 1988; Redpath et al., 1993). Previous study has shown that eEF2 can act as a biochemical sensor that is tuned to the ongoing level of mEPSC activities in hippocampal neurons (Sutton et al., 2007). Here we showed that phosphorylation (and inactivation) of eEF2 with rapamycin blocked the suppression of inhibitory synapses induced by the absence of mEPSCs. Furthermore, rapamycin treatment alone induced an increase in the MIPSC frequency, and dephosphorylation (and activation) of eEF2 with NH125 or rottlerin reduced the mIPSC frequency. Notably, the NH125 effect could be abolished by blocking CB1Rs and occluded by prior TCA treatment, suggesting that the effects due to the absence of mEPSCs and the activation of eEF2 are mediated by similar mechanisms. Through modification of the status of its phosphorylation, eEF2 may mediate the effect of mEPSC activity 
via bidirectionally modulating presynaptic properties of inhibitory synapses.

Local protein synthesis at the synaptic site is important in activity-dependent synaptic plasticity (Steward and Schuman, 2001). Such protein synthesis occurs in dendrites (Sutton et al., 2004, 2006, 2007), and in developing as well as mature axons (Beaumont et al., 2001; Zhang and Poo, 2002). Recently, Yin et al. (2006) showed that eCB-dependent LTD in the striatum and in the CA1 region of the hippocampus requires presynaptic and postsynaptic protein synthesis, respectively. Whether the eEF2dependent protein synthesis relevant for the present homeostatic suppression occurs in the presynaptic and/or postsynaptic neuron remains to be investigated.

\section{Physiological implications}

In the present study, we have shown a novel function of mEPSCsheterosynaptic maintenance of the presynaptic function of inhibitory synapses. When the mEPSC activity is silenced, both miniature and AP-evoked inhibitory synaptic activities become downregulated in a manner opposite to that of the excitatory synapses, thus helping to restore the excitation-inhibition balance and the overall activity level of the circuit. The heterosynaptic regulation shown here may also contribute to the developmental or experience-dependent refinement of neural connections. As excitatory inputs become strengthened or weakened, homeostatic changes in the efficacy of coinnervating inhibitory synapses may occur to achieve the coordinated refinement of excitatory and inhibitory inputs converging onto the same neuron, as observed in the developing Xenopus visual system (Tao and Poo, 2005).

Induction of LTP and LTD of excitatory synapses may result in presynaptic modulation of the efficacy of transmitter release, in addition to postsynaptic changes in receptor density, leading to changes in mEPSCs. Hebbian modifications of individual excitatory synapses associated with LTP/LTD may be erased by homeostatic synaptic scaling that occurs locally (Ju et al., 2004; Thiagarajan et al., 2005; Sutton et al., 2006; Hou et al., 2008). To resolve this "paradox," Rabinowitch and Segev (2008) proposed that heterosynaptic scaling of adjacent excitatory synapses of the same polarity helps to preserve the relative changes in synaptic strength associated with LTP/LTD. Heterosynaptic scaling of adjacent inhibitory synapses of the opposite polarity described here will also serve the same function in preserving Hebbian modifications of excitatory synapses in the face of local homeostatic plasticity.

\section{References}

Adermark L, Lovinger DM (2009) Frequency-dependent inversion of net striatal output by endocannabinoid-dependent plasticity at different synaptic inputs. J Neurosci 29:1375-1380.

Aoto J, Nam CI, Poon MM, Ting P, Chen L (2008) Synaptic signaling by all-trans retinoic acid in homeostatic synaptic plasticity. Neuron 60:308-320.

Arora S, Yang JM, Kinzy TG, Utsumi R, Okamoto T, Kitayama T, Ortiz PA, Hait WN (2003) Identification and characterization of an inhibitor of eukaryotic elongation factor 2 kinase against human cancer cell lines. Cancer Res 63:6894-6899.

Bacci A, Huguenard JR, Prince DA (2004) Long-lasting self-inhibition of neocortical interneurons mediated by endocannabinoids. Nature 431:312-316.

Beaumont V, Zhong N, Fletcher R, Froemke RC, Zucker RS (2001) Phosphorylation and local presynaptic protein synthesis in calcium- and calcineurin-dependent induction of crayfish long-term facilitation. Neuron 32:489-501.

Brown SP, Brenowitz SD, Regehr WG (2003) Brief presynaptic bursts evoke synapse-specific retrograde inhibition mediated by endogenous cannabinoids. Nat Neurosci 6:1048-1057.
Burrone J, O’Byrne M, Murthy VN (2002) Multiple forms of synaptic plasticity triggered by selective suppression of activity in individual neurons. Nature 420:414-418.

Chevaleyre V, Castillo PE (2003) Heterosynaptic LTD of hippocampal GABAergic synapses: a novel role of endocannabinoids in regulating excitability. Neuron 38:461-472.

Chevaleyre V, Castillo PE (2004) Endocannabinoid-mediated metaplasticity in the hippocampus. Neuron 43:871-881.

Chevaleyre V, Takahashi KA, Castillo PE (2006) Endocannabinoidmediated synaptic plasticity in the CNS. Annu Rev Neurosci 29:37-76.

Desai NS, Cudmore RH, Nelson SB, Turrigiano GG (2002) Critical periods for experience-dependent synaptic scaling in visual cortex. Nat Neurosci 5:783-789.

Diana MA, Marty A (2003) Characterization of depolarization-induced suppression of inhibition using paired interneuron-Purkinje cell recordings. J Neurosci 23:5906-5918.

Freund TF, Katona I (2007) Perisomatic inhibition. Neuron 56:33-42.

Freund TF, Katona I, Piomelli D (2003) Role of endogenous cannabinoids in synaptic signaling. Physiol Rev 83:1017-1066.

Fukudome Y, Ohno-Shosaku T, Matsui M, Omori Y, Fukaya M, Tsubokawa H, Taketo MM, Watanabe M, Manabe T, Kano M (2004) Two distinct classes of muscarinic action on hippocampal inhibitory synapses: M2mediated direct suppression and M1/M3-mediated indirect suppression through endocannabinoid signalling. Eur J Neurosci 19:2682-2692.

Gerdeman GL, Ronesi J, Lovinger DM (2002) Postsynaptic endocannabinoid release is critical to long-term depression in the striatum. Nat Neurosci 5:446-451.

Glickfeld LL, Scanziani M (2006) Distinct timing in the activity of cannabinoid-sensitive and cannabinoid-insensitive basket cells. Nat Neurosci 9:807-815.

Gschwendt M, Kittstein W, Marks F (1994) Elongation factor-2 kinase: effective inhibition by the novel protein kinase inhibitor rottlerin and relative insensitivity towards staurosporine. FEBS Lett 338:85-88.

Hou Q, Zhang D, Jarzylo L, Huganir RL, Man HY (2008) Homeostatic regulation of AMPA receptor expression at single hippocampal synapses. Proc Natl Acad Sci U S A 105:775-780.

Ibata K, Sun Q, Turrigiano GG (2008) Rapid synaptic scaling induced by changes in postsynaptic firing. Neuron 57:819-826.

Jørgensen R, Merrill AR, Andersen GR (2006) The life and death of translation elongation factor 2. Biochem Soc Trans 34:1-6.

Ju W, Morishita W, Tsui J, Gaietta G, Deerinck TJ, Adams SR, Garner CC, Tsien RY, Ellisman MH, Malenka RC (2004) Activity-dependent regulation of dendritic synthesis and trafficking of AMPA receptors. Nat Neurosci 7:244-253.

Jung KM, Astarita G, Zhu C, Wallace M, Mackie K, Piomelli D (2007) A key role for diacylglycerol lipase-alpha in metabotropic glutamate receptordependent endocannabinoid mobilization. Mol Pharmacol 72:612-621.

Katona I, Freund TF (2008) Endocannabinoid signaling as a synaptic circuit breaker in neurological disease. Nat Med 14:923-930.

Kilman V, van Rossum MC, Turrigiano GG (2002) Activity deprivation reduces miniature IPSC amplitude by decreasing the number of postsynaptic $\operatorname{GABA}(\mathrm{A})$ receptors clustered at neocortical synapses. J Neurosci 22:1328-1337.

Kim J, Tsien RW (2008) Synapse-specific adaptations to inactivity in hippocampal circuits achieve homeostatic gain control while dampening network reverberation. Neuron 58:925-937.

Koester HJ, Johnston D (2005) Target cell-dependent normalization of transmitter release at neocortical synapses. Science 308:863-866.

Kreitzer AC, Regehr WG (2001a) Retrograde inhibition of presynaptic calcium influx by endogenous cannabinoids at excitatory synapses onto Purkinje cells. Neuron 29:717-727.

Kreitzer AC, Regehr WG (2001b) Cerebellar depolarization-induced suppression of inhibition is mediated by endogenous cannabinoids. J Neurosci $21: R C 174$.

Lu JT, Li CY, Zhao JP, Poo MM, Zhang XH (2007) Spike-timing-dependent plasticity of neocortical excitatory synapses on inhibitory interneurons depends on target cell type. J Neurosci 27:9711-9720.

Maejima T, Hashimoto K, Yoshida T, Aiba A, Kano M (2001) Presynaptic inhibition caused by retrograde signal from metabotropic glutamate to cannabinoid receptors. Neuron 31:463-475.

Maffei A, Turrigiano GG (2008) Multiple modes of network homeostasis in visual cortical layer 2/3. J Neurosci 28:4377-4384. 
Maffei A, Nelson SB, Turrigiano GG (2004) Selective reconfiguration of layer 4 visual cortical circuitry by visual deprivation. Nat Neurosci 7:1353-1359.

Maffei A, Nataraj K, Nelson SB, Turrigiano GG (2006) Potentiation of cortical inhibition by visual deprivation. Nature 443:81-84.

Marder E, Prinz AA (2003) Current compensation in neuronal homeostasis. Neuron 37:2-4.

McKinney RA, Capogna M, Dürr R, Gähwiler BH, Thompson SM (1999) Miniature synaptic events maintain dendritic spines via AMPA receptor activation. Nat Neurosci 2:44-49.

Murthy VN, Schikorski T, Stevens CF, Zhu Y (2001) Inactivity produces increases in neurotransmitter release and synapse size. Neuron 32:673-682.

O’Brien RJ, Kamboj S, Ehlers MD, Rosen KR, Fischbach GD, Huganir RL (1998) Activity-dependent modulation of synaptic AMPA receptor accumulation. Neuron 21:1067-1078.

Ohno-Shosaku T, Maejima T, Kano M (2001) Endogenous cannabinoids mediate retrograde signals from depolarized postsynaptic neurons to presynaptic terminals. Neuron 29:729-738.

Ohno-Shosaku T, Shosaku J, Tsubokawa H, Kano M (2002) Cooperative endocannabinoid production by neuronal depolarization and group I metabotropic glutamate receptor activation. Eur J Neurosci 15:953-961.

Ohno-Shosaku T, Matsui M, Fukudome Y, Shosaku J, Tsubokawa H, Taketo MM, Manabe T, Kano M (2003) Postsynaptic M1 and M3 receptors are responsible for the muscarinic enhancement of retrograde endocannabinoid signalling in the hippocampus. Eur J Neurosci 18:109-116.

Piomelli D (2003) The molecular logic of endocannabinoid signalling. Nat Rev Neurosci 4:873-884.

Proud CG (2006) Regulation of protein synthesis by insulin. Biochem Soc Trans 34:213-216.

Rabinowitch I, Segev I (2008) Two opposing plasticity mechanisms pulling a single synapse. Trends Neurosci 31:377-383.

Redpath NT, Price NT, Severinov KV, Proud CG (1993) Regulation of elongation factor-2 by multisite phosphorylation. Eur J Biochem 213: $689-699$

Reyes A, Lujan R, Rozov A, Burnashev N, Somogyi P, Sakmann B (1998) Target-cell-specific facilitation and depression in neocortical circuits. Nat Neurosci 1:279-285.

Robbe D, Kopf M, Remaury A, Bockaert J, Manzoni OJ (2002) Endogenous cannabinoids mediate long-term synaptic depression in the nucleus accumbens. Proc Natl Acad Sci U S A 99:8384-8388.

Ronesi J, Gerdeman GL, Lovinger DM (2004) Disruption of endocannabinoid release and striatal long-term depression by postsynaptic blockade of endocannabinoid membrane transport. J Neurosci 24:1673-1679.

Ryazanov AG, Shestakova EA, Natapov PG (1988) Phosphorylation of elongation factor 2 by EF-2 kinase affects rate of translation. Nature 334: $170-173$.

Safo PK, Regehr WG (2005) Endocannabinoids control the induction of cerebellar LTD. Neuron 48:647-659.

Saitoe M, Schwarz TL, Umbach JA, Gundersen CB, Kidokoro Y (2001) Absence of junctional glutamate receptor clusters in Drosophila mutants lacking spontaneous transmitter release. Science 293:514-517.
Schlicker E, Kathmann M (2001) Modulation of transmitter release via presynaptic cannabinoid receptors. Trends Pharmacol Sci 22:565-572.

Seeburg DP, Sheng M (2008) Activity-induced Polo-like kinase 2 is required for homeostatic plasticity of hippocampal neurons during epileptiform activity. J Neurosci 28:6583-6591.

Sjöström PJ, Turrigiano GG, Nelson SB (2003) Neocortical LTD via coincident activation of presynaptic NMDA and cannabinoid receptors. Neuron 39:641-654.

Steward O, Schuman EM (2001) Protein synthesis at synaptic sites on dendrites. Annu Rev Neurosci 24:299-325.

Sutton MA, Wall NR, Aakalu GN, Schuman EM (2004) Regulation of dendritic protein synthesis by miniature synaptic events. Science 304:19791983.

Sutton MA, Ito HT, Cressy P, Kempf C, Woo JC, Schuman EM (2006) Miniature neurotransmission stabilizes synaptic function via tonic suppression of local dendritic protein synthesis. Cell 125:785-799.

Sutton MA, Taylor AM, Ito HT, Pham A, Schuman EM (2007) Postsynaptic decoding of neural activity: eEF2 as a biochemical sensor coupling miniature synaptic transmission to local protein synthesis. Neuron 55:648-661.

Tao HW, Poo MM (2005) Activity-dependent matching of excitatory and inhibitory inputs during refinement of visual receptive fields. Neuron 45:829-836.

Thiagarajan TC, Lindskog M, Tsien RW (2005) Adaptation to synaptic inactivity in hippocampal neurons. Neuron 47:725-737.

Trettel J, Levine ES (2002) Cannabinoids depress inhibitory synaptic inputs received by layer $2 / 3$ pyramidal neurons of the neocortex. J Neurophysiol $88: 534-539$.

Turrigiano G (2007) Homeostatic signaling: the positive side of negative feedback. Curr Opin Neurobiol 17:318-324.

Turrigiano GG (2008) The self-tuning neuron: synaptic scaling of excitatory synapses. Cell 135:422-435.

Turrigiano GG, Leslie KR, Desai NS, Rutherford LC, Nelson SB (1998) Activity-dependent scaling of quantal amplitude in neocortical neurons. Nature 391:892-896.

Varma N, Carlson GC, Ledent C, Alger BE (2001) Metabotropic glutamate receptors drive the endocannabinoid system in hippocampus. J Neurosci 21:RC188.

Wierenga CJ, Ibata K, Turrigiano GG (2005) Postsynaptic expression of homeostatic plasticity at neocortical synapses. J Neurosci 25:2895-2905.

Wierenga CJ, Walsh MF, Turrigiano GG (2006) Temporal regulation of the expression locus of homeostatic plasticity. J Neurophysiol 96:2127-2133.

Wilson RI, Nicoll RA (2001) Endogenous cannabinoids mediate retrograde signalling at hippocampal synapses. Nature 410:588-592.

Yin HH, Davis MI, Ronesi JA, Lovinger DM (2006) The role of protein synthesis in striatal long-term depression. J Neurosci 26:11811-11820.

Zhang W, Linden DJ (2003) The other side of the engram: experiencedriven changes in neuronal intrinsic excitability. Nat Rev Neurosci 4: 885-900.

Zhang X, Poo MM (2002) Localized synaptic potentiation by BDNF requires local protein synthesis in the developing axon. Neuron 36:675688. 